\title{
Liaison Psychiatry in a Burns Unit
}

\author{
S. OlivierI, Consultant Psychiatrist, Basingstoke District Hospital, Park Prewett, Basingstoke, Hants.; formerly trainee \\ Senior Registrar, Wessex Region
}

Liaison psychiatry is in a developmental stage in the UK and the opportunity to be trained in this special area at Senior Registrar level is rare. The Wessex Rotation for Senior Registrars is therefore privileged to be able to offer an attachment to Odstock Hospital, Salisbury, where the Spinal and Plastic Regional Units are based. The local psychiatric service offers consultations to both.Units, the senior registrar having opted for one session a week with the Burns Unit. He is supervised by the consultant psychiatrist who spends two weekly sessions in liaison with the special Unit.

Precipitating and complicating psychiatric factors are common among victims of burns but surprisingly little has been published in the UK on the care of the psychological and psychiatric sequelae of burns. Most of the literature comes from the United States and the greatest emphasis seems to be placed on children rather than on adult victims. There is in fact a great deal of scope for a broad psychiatric intervention in this setting and the Wessex Unit, which cares for children and adults, offers a particularly good opportunity for instituting prompt psychological intervention and prophylaxis, and for research. Within the system of the liaison activities, five main ones can be identified.

(i) Team meetings. Plastic surgery has in common with psychiatry a treatment approach by a multi-disciplinary team. Weekly meetings involving the nursing and surgical staff, occupational therapist, physiotherapist, social worker, psychiatrist are occasions where not only clinical and management decisions are taken, discussed and communicated, but when grievances, problems in the professional relationship, difficulties and anxieties can be voiced and discussed. This fosters a high working morale particularly among the nurses who are most continuously and closely in contact with the suffering and distress of the patients and their families. Our Unit, being a Regional one, has to plan longterm care and rehabilitation for the patients once they return to their districts. The psychiatrist supervises the communication of clear and simple guide-lines of a comprehensive package which considers the patients' needs and their social, family, medical, psychological and rehabilitative aspects.

(ii) Staff group. The most difficult occasions for the carers of these patients are those when severe cases with extensive burns are admitted. It is then fundamental to allow the nurses to voice their feelings and to share and explore with them some of their anxieties, preoccupations and fantasies. Nurses are also greatly involved in the support of the patients' families and need to be supported in this highly involving and emotionally demanding commitment. Staff morale is, however, quite high in the Unit and only occasionally are these specific sessions requested. It is interesting that the surgeons feel that it is only for the nurses to face up to the emotional issues involved in the care of the patients and their families. (iii) Patients assessment. This is the commonest of the liaison activities. The disorders most frequently met are alcoholism and functional psychoses in the young and dementia in the elderly. The concept of assessment implies a psychotherapeutic intervention which can be associated with pharmacological support. Patients who recover from even minor burns ask themselves how their lives will be with the scars now permanently on their bodies. This event can be equated to a mourning reaction which often involves the patients' families. The regression and behavioural disturbances associated with it can create a great deal of tension within the Unit. The patient and his family are helped through this crisis and then further supported through a gradual process of adaptation and return to an optimal level of functioning. A special category of patients are those who attempt suicide by self-immolation. They frequently suffer from primary psychiatric disorders, chiefly endogenous depressions and schizophrenia. The consultation at ward level can, in these cases, involve the psychiatric nurse as a preliminary phase towards full psychiatric care and rehabilitation.

(iv) Teaching. Teaching is performed in informal and formal sessions when the psychiatrist discusses the patients with his colleagues and the ancillary agencies. It is however useful to have one or more formal sessions when specific academic input on the epidemiology and the psychological and social consequences of burns can be presented to non-psychiatric carers.

(v) Research. There is a great deal of scope for epidemiological and follow up studies on the psychological consequences of burns. Areas of investigation that could be further studied are victims of attempted suicide, elderly victims of accidental burns, children and their families, social responses and adjustment to permanent scarring.

Comment Attachment to a Burns Unit as a liaison psychiatrist is a rewarding experience. The plastic surgeon will usually find this collaboration useful and the establishment of a harmonious working relationship can be fruitful for specialists and collaborators. The last 10 years have seen the development of forensic and geriatric psychiatry. The future will hopefully see the flourishing of liaison psychiatry and trainees should therefore be offered some experience and supervision in it. For this to happen, it is necessary that consultants with special interest in liaison psychiatry are appointed in every district, particularly in those where illnesses associated with severe psychological disturbances and problems of readjustment are treated in specialised units.

REFERENCE

Thomas, C. J. (1985) Does medicine need liaison psychiatry? Bulletin of the Royal College of Psychiatrists, 9, 157-158. 